\title{
Percepção dos receptores sanguíneos quanto ao processo transfusional
}

\author{
Blood transfusion receivers' perception of the transfusion process \\ Percepción de transfusión de sangre en el caso de los receptores
}

\author{
Maritza Margareth Faquetti', Raquel Luzia Rosa", Maria Lígia dos Reis Bellaguarda"', \\ Daniele Delacanal Lazzari"', Adriana Dutra TholI"', Cladis Loren Kiefer Moraes ${ }^{\mathrm{IV}}$ \\ 'Centro de Hematologia e Hemoterapia de Santa Catarina. Florianópolis-SC, Brasil. \\ "Unimed. Florianópolis-SC, Brasil. \\ I"' Universidade Federal de Santa Catarina, Programa de Pós-Graduação em Enfermagem. Florianópolis-SC, Brasil. \\ Iv Secretaria de Estado da Saúde de Santa Catarina. Florianópolis-SC, Brasil.
}

\author{
Submissão: 17-01-2013 Aprovação: 11-10-2014
}

\section{RESUMO}

Pesquisa qualitativa, exploratória descritiva, que objetivou conhecer a percepção dos receptores sanguíneos quanto ao processo transfusional. A pesquisa foi realizada em uma unidade de hemoterapia de um município da região sul do Brasil e os dados foram analisados por meio do Discurso do Sujeito Coletivo. Foram entrevistados, por meio de instrumento semiestruturado, onze pacientes, homens e mulheres entre 30 e 95 anos, em recuperação pós-cirúrgica de cirurgia cardíaca, submetidos à transfusão sanguínea. Emergiram quatro Ideias Centrais: Perda e reposição sanguínea; Preservação da vida; Reconhecimento do processo transfusional e Segurança transfusional. A percepção sobre a mudança que os pós-transfundidos começam a vivenciar a partir do processo transfusional traz à tona uma ressignificação da própria vida. Este estudo mostrou que os pacientes transfundidos percebem o processo transfusional como uma alternativa de sobrevivência e, mesmo tendo conhecimento sobre o processo e seus significados, permanecem receios e angústias que podem ser minimizados pela equipe multiprofissional.

Descritores: Transfusão Sanguínea; Percepção; Enfermagem.

ABSTRACT
Qualitative research, descriptive exploratory, aimed to know the perception of blood transfusion recipients as to the process. The research was carried out at a blood bank in a city in southern Brazil, and the data were analyzed using the Collective Subject Discourse. Were interviewed using a semistructured instrument, eleven patients, men and women between 30 and 95 years, post-surgical recovery of cardiac surgery, underwent blood transfusion. Four central ideas emerged: loss and blood replacement; Preservation of life; Recognition of the transfusion process; and transfusion safety. The perception about the change that post-transfusion begin to live from the transfusion process raises a reframing of life itself. This study showed that transfused patients perceive the transfusion process as a means of survival, and even having knowledge about the process and their meanings, there is the permanence of fears and anxieties that can be minimized by the multidisciplinary team.

Key words: Blood Transfusion; Perception; Nursing.

\section{RESUMEN}

Investigación cualitativa, de tipo exploratorio descriptivo, con el objetivo de conocer la percepción de los receptores de transfusiones de sangre en cuanto al proceso. La investigación se llevó a cabo en un banco de sangre en una ciudad en el sur de Brasil, y los datos fueron analizados utilizando el Discurso del Sujeto Colectivo. Fueron entrevistados mediante un instrumento semi-estructurado, once pacientes, hombres y mujeres de entre 30 y 95 años de recuperación post-quirúrgica de la cirugía cardíaca, se sometió a una transfusión de sangre. Cuatro ideas centrales surgieron: la pérdida y reemplazo de sangre; La preservación de la vida; Reconocimiento del proceso de transfusión; y seguridad de las transfusiones. La percepción sobre el cambio que después de la transfusión comenzar a vivir desde el proceso de transfusión plantea una reformulación de la vida misma. Este estudio mostró que los pacientes transfundidos perciben el proceso de transfusión como un medio de supervivencia, e incluso tener conocimiento sobre el proceso y sus significados, no es la permanencia de los temores y ansiedades que pueden minimizarse por el equipo multidisciplinario.

Palavras clave: Transfusión Sanguinea; Percepcion; Enfermería. 


\section{INTRODUÇÃO}

Hemotransfusão é a administração de diversos produtos sanguíneos por via endovenosa, configurando-se em uma tecnologia de extrema importância na terapêutica moderna. É um procedimento complexo e, por esta razão, requer conhecimento específico por parte dos profissionais envolvidos no processo, haja vista, a necessidade de cuidados especializados na administração e na identificação de complicações agudas ou tardias ${ }^{(1)}$.

Por ser a equipe de enfermagem a responsável pela administração e controle do processo transfusional, cabe a ela observar o paciente antes da transfusão, avaliar seu estado durante e acompanhá-lo ao término desta, prevenindo possíveis complicações ou reações transfusionais ${ }^{(2)}$. Neste contexto, a equipe de enfermagem é de grande importância, bem como a qualidade dos controles e registros, de maneira que se torna imprescindível amplos conhecimentos para identificação de possíveis anormalidades ao longo de todo o processo. Profissionais sem domínio de conhecimentos em hemoterapia ou habilidade técnica podem favorecer a ocorrência de erros minimizando a segurança transfusional ${ }^{(3)}$.

Neste contexto, as transformações nas práticas de hemoterapia trouxeram consigo novos deveres e obrigações relacionadas à bioética acarretando mudanças tanto na qualidade da assistência prestada, quanto na percepção dos pacientes. Há novas e melhores terapias, há mais informações sobre elas, porém, o medo e a angústia relacionados ao processo permanecem presentes em muitos casos, principalmente, quando se observa a realidade dos receptores ${ }^{(4)}$.

Procedimentos médicos tais como as cirurgias cardíacas e os transplantes acabaram por aumentar consideravelmente a demanda por transfusões sanguíneas ${ }^{(5)}$. No Brasil, não há dados disponíveis sobre a demanda por sangue, porém estimativas indicam cerca de três milhões e seiscentas mil transfusões todos os anos ${ }^{(6)}$. Os estudos sobre as percepções dos receptores ainda são incipientes, embora exista número significativo de pesquisas sobre o processo de doação em si e a percepção dos doadores.

Os receptores de transfusão sanguínea são passíveis de dúvidas, incertezas e inseguranças, que possivelmente podem interferir no processo transfusional. Explorar situações e questionamentos que contemplem os sentimentos dos receptores torna-se atividade significativa, na medida em que pode servir para a elaboração de estratégias que minimizem os riscos ou desconfortos que essa prática pode vir a gerar.

A realização deste estudo foi impulsionada pelo cotidiano de trabalho em unidade de hemoterapia e a observação da lacuna existente no que se refere à assistência aos pacientes receptores de hemotransfusão, além da contribuição da enfermagem na terapia com hemoderivados. Desta forma, o objetivo geral deste estudo foi conhecer a percepção dos receptores sanguíneos quanto ao processo transfusional.

\section{MÉTODO}

Pesquisa qualitativa, exploratória descritiva, realizada em uma clínica privada de um município da região sul do Brasil, na qual há um serviço especializado em Hemoterapia que atende pacientes pós-cirurgia cardíaca, dentre outros. Os participantes deste estudo foram 11 sujeitos (quatro mulheres e sete homens), receptores de hemocomponentes, em processo transfusional para reabilitação pós-cirurgia cardíaca. Todos os receptores de sangue participaram deste estudo mediante aceite e assinatura prévia do Termo de Consentimento Livre e Esclarecido, respeitando os aspectos abordados na resolução 466/12 do Conselho Nacional de Saúde. Este estudo foi aprovado pela Comissão de Ética e Pesquisa da Universidade do Vale do Itajaí, sob o protocolo 503/09b.

Foram incluídos no estudo pacientes maiores de idade e em condições clínicas satisfatórias para participar da entrevista. Foram excluídos os sujeitos que se encontrassem ausentes da clínica no momento da coleta de dados, por conta da realização de exames ou outros procedimentos. A coleta de dados ocorreu no período de dezembro de 2011.

A técnica utilizada para coleta de dados foi a entrevista, com média de duração de 30 minutos. Utilizou-se um questionário contendo questões abertas relacionadas ao processo transfusional que intencionaram aprofundar as questões relativas à percepção dos sujeitos sobre o momento, significado atribuído ao sangue e ao processo e sentimentos relacionados. $\mathrm{Na}$ análise dos dados, foi utilizada a técnica do Discurso do Sujeito Coletivo (DSC), em que se procura o pensar expresso de forma discursiva por um conjunto de sujeitos, sobre determinado assunto. O DSC se organiza em quatro figuras metodológicas: Ancoragem (AC), que é a manifestação linguística explícita de uma teoria, ideologia, ou crença que o autor do discurso declara; Expressões-chave $(\mathrm{ECH})$ que são trechos do discurso individual, devendo ser destacados pelo pesquisador, reveladores da essência do conteúdo do discurso; Ideia Central (IC), expressão que descreve a partir da leitura dos textos coletados, o sentido de cada um dos discursos, que revelam o tema do depoimento ou sobre o que o sujeito está falando; o DSC é composto pelas $\mathrm{ECH}$ s que tem a mesma $\mathrm{IC}^{(7)}$.

A análise do material foi feita extraindo-se de cada um dos depoimentos a Ideia Central, Ancoragens e suas correspondentes Expressões-Chave, a fim de que compusessem um ou vários discursos-síntese, na primeira pessoa do singular. Dessa forma, o sujeito coletivo se expressou por meio de um discurso emitido no que se poderia chamar de primeira pessoa coletiva do singular, pois, várias pessoas discursaram sobre determinado tema, mas não formam um nós, mas, um eu coletivizado ${ }^{(7)}$.

\section{RESULTADOS E DISCUSSÃO}

\section{Caracterização dos participantes do estudo}

Dentre os indivíduos participantes, quatro eram do sexo feminino e sete do sexo masculino. As idades variaram entre 30 e 95 anos. Em relação à religião, 63\% eram católicos, 27\% evangélicos, 9\% kardecistas. Quanto ao estado civil, 72\% eram casados, $18 \%$ viúvos e $9 \%$ desquitados.

Os resultados são apresentados de acordo com os temas e a transcrição dos discursos do sujeito coletivo (DSC) e ideias centrais (IC), que embasaram a análise dos dados. Cabe ressaltar que o discurso representa o coletivo dos pacientes receptores 
de hemocomponentes entrevistados e, conforme a técnica apresenta-se como se fosse o relato de uma única pessoa.

\section{DISCURSO DO SUJEITO COLETIVO}

$\mathbf{1}^{\mathrm{a}}$ Pergunta: Você tem conhecimento de por que está recebendo esta transfusão?

\section{Perda e reposição sanguínea. (IC)}

Sim, devido à perda excessiva de sangue na cirurgia cardíaca a que me submeti, estava com o hematócrito muito baixo e mal estar geral, logo precisei de muito sangue para repor hemácias e melhorar a oxigenação. (DSC)

A percepção declarada no discurso evidencia clareza por parte dos receptores da real necessidade de submeterem-se ao processo transfusional. A medicina transfusional é um complexo processo que depende de uma equipe interdisciplinar ${ }^{(8)}$, que exerce um papel fundamental na segurança da hemotransfusão e cuja responsabilidade consiste, inclusive, em manter o paciente informado acerca dos procedimentos a que é submetido.

A atividade de orientação dos pacientes receptores de transfusão sanguínea por parte dos profissionais de saúde é indispensável, para que haja colaboração destes e sucesso de todo o processo. Neste contexto, os profissionais da saúde não apenas administram transfusões, mas também devem conhecer suas indicações, providenciar e checar dados importantes na prevenção de erros, orientar os pacientes sobre a transfusão, detectar, comunicar, atuar e documentar todo processo transfusional ${ }^{(9)}$.

As informações e características da doença ou de procedimentos a que o paciente será submetido configura-se numa das estratégias educativas adotadas pelas enfermeiras a fim de promover a adesão dos pacientes à terapêutica proposta.

Adesão pode ser definida como uma colaboração ativa entre o paciente e a equipe multiprofissional, onde o comportamento do paciente corresponde às recomendações de médicos, enfermeiros, nutricionistas, etc e é demonstrada, por vezes, na correspondência do paciente às solicitações, comparecimento a consultas, seguimento das prescrições e da terapêutica de uma forma geral e ainda, mudança no estilo de vida(10).

A não adesão do paciente pode vir a comprometer o tratamento em função de não favorecer a participação ativa do paciente em seu processo de cura ou manejo da doença. A adesão é um fator relevante que por vezes interfere nos resultados positivos de um tratamento de saúde. Para tanto, uma efetiva comunicação interpessoal entre equipe e paciente é condição essencial.

Os participantes deste estudo, após a realização da cirurgia cardíaca, têm na transfusão sanguínea a continuidade do cuidado e também do tratamento. O reconhecimento das experiências, modos de viver e ser saudável destes pacientes assume significado para a Enfermagem, na medida em que se compreende que as vivências destes sujeitos podem contribuir positivamente ou não para as relações de cuidado ao interferir no autocuidado e reabilitação(11). Outro fator que deve ser levado em consideração são os índices de ansiedade e depressão presentes no pós-operatório de pacientes com patologias cardíacas pois, a internação prolongada é um dos fatores que pode favorecer as dificuldades emocionais, assim como a continuidade do tratamento por intermédio das transfusões sanguíneas acarretam perturbações no repouso e na autonomia do paciente ${ }^{(12)}$. O conhecimento e o entendimento das razões acerca da necessidade de transfusão sanguínea ou mesmo da condição de saúde e procedimentos realizados, podem ajudar o paciente, contribuindo positivamente para adesão à terapêutica proposta e proporcionando segurança.

Estudo que descreveu as necessidades do paciente no pós-operatório de cirurgia cardíaca apontou que há preocupação dos enfermeiros em diminuir o déficit de conhecimento dos pacientes e familiares por meio de atividades de educação em saúde, a fim de promover o autocuidado, influenciando positivamente na recuperação dos pacientes ${ }^{(9)}$.

$2^{a}$ Pergunta: $O$ que significa o sangue para você? $O$ que ele representa?

Preservação da vida. (IC)

É a garantia de vida dentro do ser humano, logo representa a vida. Enfim, é um composto necessário para melhora clínica que mantém, preserva e dá continuidade à vida. (DCS)

Quando se trata de pensar sobre o sangue, os receptores demonstram que há mitos, crenças, dogmas, que transformam inconscientemente objetos e formas em símbolos que lhes atribui expressões tais como "o sangue é vida". O discurso mostra o forte significado que atribuem ao ato de receber sangue, os benefícios que ele traz ao quadro geral de saúde e ao bem estar. Observa-se, que os benefícios da hemotransfusão relatadas no discurso superam os riscos que dele e de sua manipulação podem advir.

Nesta perspectiva a orientação e o conhecimento da enfermeira e da equipe de saúde atuam como um diferencial para o sucesso da terapêutica. Outro fator que influencia o receptor sanguíneo nesta compreensão do sangue como representação da vida são os seus sistemas de significações, símbolos culturais e religiosos. Durante toda a história da humanidade, o sangue sempre esteve relacionado a mitos e cosmogonias, sendo-lhe atribuídos vários significados. Os significados atribuídos ao sangue refletem diretamente nos sistemas de significados atribuídos a transfusão sanguínea. Interpretar os significados e, principalmente o simbolismo do sangue relacionado à transfusão sanguínea possibilitará, por meio da atuação profissional, a redução ou a minimização dos conflitos religiosos culturais e sociais respeitando-se o ser humano e atuando-se na promoção e recuperação da saúde ${ }^{(13)}$.

O ser humano é amplamente influenciado pela realidade sociocultural em que está inserido e suas reações aos estímulos se dão com base no significado que as situações representam para ele. A realidade é interpretada e recebe sentido na medida em que corresponde às expectativas do sujeito, sendo este um dos diferenciais do ser humano com relação a outras espécies: a capacidade de produzir símbolos e construir o mundo e função de experiências empíricas e sensoriais ${ }^{(14)}$. 
A vinculação da vida ao sangue é um conceito antigo, sendo que este significado foi sendo incorporado culturalmente ao longo dos anos. A função de manutenção da vida foi atribuída, pelos informantes, ao sangue que circula no organismo humano, enquanto que sua ausência pode ser interpretada como morte ${ }^{(14)}$.

Na cultura cristã, a palavra "sangue" possui forte relação com as emoções. Quando associado ao coração, este vocábulo está presente na literatura, nas artes e nas ciências. Desta forma, o sangue de um doador é considerado uma parte de outro sujeito e, quem o recebe numa transfusão faz parte de um processo de solidariedade, não isento de fortes simbolismos, representando não apenas a vida, mas sua continuidade ${ }^{(15)}$.

$3^{a}$ Pergunta: Transfusão sanguínea: como é este processo para você?

\section{Reconhecimento do processo transfusional. (IC)}

Tem certas horas que não se têm muitas escolhas, quando se perde muito sangue precisa ser reposto. É a entrada de sangue no corpo com suas propriedades, doado de outras pessoas, um bem necessário que devolve a vida, um procedimento simples, porém com vários riscos. (DCS)

Dos relatos advindos dos receptores, apesar da consciência de o ato de receber a transfusão representar riscos, a necessidade desta para a manutenção da vida torna-se aceitável. Observa-se que a relação de ajuda é essencial, para que a troca de experiência entre profissionais e pacientes possa sanar dúvidas, ansiedades, angústias perante o ato transfusional. Importante a inclusão de programas de capacitação, atualização e educação permanente para os profissionais envolvidos na terapêutica transfusional.

A Hemoterapia é uma especialidade complexa e interdisciplinar, que reúne médicos, enfermeiros, bioquímicos, assistentes sociais e outros pesquisadores de vários ramos da ciência, contribuindo para a recuperação da saúde. A medicina transfusional tem como objetivo garantir a qualidade e a quantidade do sangue, componentes e serviços oferecidos aos receptores, a indicação adequada ao uso do sangue e seus componentes, atende preceitos da hemoterapia seletiva, vem propiciando uma maior otimização das unidades de coleta e redução quantitativa na exposição dos receptores ${ }^{(16)}$.

Em um discurso anterior, evidenciou-se que há conhecimento por parte dos receptores quando aos significados de receber uma transfusão sanguínea. Este discurso, advindo do terceiro questionamento, reforça a segurança sobre a necessidade deste processo, embora, carregue consigo mensagem real de que não há escolha. A experiência pela qual passa o receptor é legítima e este parece compreender a relação de dependência que há entre esta terapêutica e a necessidade de manutenção da vida.

O entendimento sobre as representações da saúde e da doença varia culturalmente a cada lugar e momento histórico. Desta forma, os pacientes podem apoiar-se em inúmeros conceitos, símbolos ou estruturas interiorizadas para interpretar suas experiências $^{(17)}$. As narrativas destes sujeitos mostram a necessidade inquestionável de reposição sanguínea para "repor o sangue perdido". 4a Pergunta: Quais as suas maiores dúvidas quanto ao processo de transfusão?

\section{Segurança transfusional. (IC)}

Tenho medo de pegar uma doença transmissível, de rejeição e até morrer com sangue contaminado, advindas de doadores doentes. Sempre há dúvida quanto à aceitação do nosso corpo, pode ocorrer reação adversa se trocarem por algum descuido o meu tipo sanguíneo e receber um sangue não compatível, só pode fazer transfusão com a mesma tipagem sanguínea. (DCS)

O discurso evidencia a apreensão dos receptores sanguíneos quanto ao processo de recepção do sangue, seus medos e incertezas referentes à compatibilidade entre doador e receptor, além da transfusão como meio de transmissibilidade de doenças. $\mathrm{O}$ sangue sendo um veículo para a transmissão de doenças apresenta-se no imaginário social como o modo facilitado de adoecimento por patologias que sinalizam risco de morte. No Brasil, a regulamentação da Hemoterapia é realizada pela Agência Nacional de Vigilância Sanitária (ANVISA), através da Resolução da Diretoria Colegiada (RDC) n¹53 de junho de 2004, que determina o Regulamento Técnico para os procedimentos hemoterápicos, incluindo a coleta, o processamento, a testagem, o armazenamento, o transporte, o controle de qualidade e o uso humano de sangue, e seus componentes, obtidos do sangue venoso, do cordão umbilical, da placenta e da medula óssea ${ }^{(18)}$.

A triagem dos doadores de sangue é um procedimento ético, onde todas as declarações recebidas são mantidas em sigilo, para preservação de seus interesses. Considera-se de vital importância criar mecanismos para qualidade dos resultados positivos e/ ou inconclusivos. Os receptores de sangue submetem-se a testes pré-transfusionais para determinação do grupo $\mathrm{ABO}$ e fator Rh, pesquisa de anticorpos irregulares e compatibilidade sanguínea. As amostras de sangue coletadas dos doadores ficam armazenadas durante seis meses, enquanto do receptor dez $\operatorname{dias}^{(19)}$.

À equipe de saúde está reservado o esclarecimento, a atenção e o cuidado desde o manuseio até a administração e manutenção do receptor. A utilização do sangue em transfusões exige o consentimento do receptor, porque existem aspectos jurídicos que legitimizam a prática transfusional. Várias etapas jurídicas antecedem o processo de transfusão, existe inclusive a responsabilidade do Estado pela fiscalização dos hemocentros.

Os medos dos participantes deste estudo estão centrados, basicamente, na possibilidade de transmissão de doenças, na rejeição ao sangue do doador e na possibilidade de morrer em função da transfusão. A segurança transfusional assumiu destaque nos últimos anos, principalmente a partir da década de 80, com a descoberta do vírus da imunodeficiência humana (HIV), acelerando o desenvolvimento de práticas seguras para a terapêutica transfusional(20)

A segurança do paciente é afetada por riscos que são inerentes à terapia transfusional. Porém, políticas públicas especificas fomentaram o desenvolvimento de processos que a tornam não apenas uma especialidade complexa, mas também uma das mais seguras atualmente ${ }^{(21)}$. 
Prevenir, eliminar ou minimizar os riscos envolvidos na prática transfusional, garantindo a eficácia dos hemocomponentes por meio de vigilância constante é papel dos profissionais da saúde envolvidos com todo o processo, de modo a transmitir confiabilidade para o paciente. Desta forma, o registro de reações transfusionais ou quaisquer problemas de ordem técnica, passa a ser um imperativo na busca pela qualidade. A Agência Nacional de Vigilância Sanitária informou que, no ano de 2011, ocorreram 5.340 reações transfusionais, com uma subnotificação estimada de $50,1 \%{ }^{(22)}$.

Estudo realizado em 226 centros de sangue do núcleo de hemoterapia e agências transfusionais em 178 municípios do estado de Minas Gerais, Brasil, concluiu-se que a incidência de notificação e investigação das causas de reações transfusionais foi maior nos serviços de transfusão que possuíam comitê transfusional atuante, embora, no geral, o desempenho dos comitês de transfusão tenha sido considerado incipiente, carente de melhores formas de organização ${ }^{(23)}$.

No caso dos participantes deste estudo, por terem sido submetidos a inúmeros procedimentos invasivos e pela necessidade de continuidade de tratamento pós-operatório de cirurgia cardíaca, o processo transfusional possui forte significado, uma vez que dele depende a qualidade de suas vidas. Para tanto é necessário, cada vez mais, qualificar o cuidado profissional, desenvolvendo estratégias de acolhimento eficazes, que possam contribuir para minimizar sofrimentos e diminuir ao máximo as dúvidas de pacientes e familiares.

\section{CONSIDERAÇÕES FINAIS}

Este estudo oportunizou aproximação aos modos de pensar e perceber o estado de saúde-doença de pacientes que necessitaram de intervenção transfusional. Partindo do pressuposto que cada ser humano traz consigo sentimentos, valores e crenças filosóficas e que a necessidade de cirurgia cardíaca e posterior continuidade do tratamento por meio do processo transfusional são situações que assumem profundo significado simbólico para o imaginário destes pacientes, percebe-se a necessidade de amplo acolhimento por parte da equipe de enfermagem, estabelecendo confiança e contribuindo para o sucesso do tratamento e reabilitação.

A pesquisa possibilitou conhecimentos sobre a percepção e o significado do sangue e a percepção de que as preocupações dos receptores sanguíneos são da ordem de possíveis incertezas com relação a sua sobrevivência. As transformações no estado de saúde do ser humano e a complexidade das mudanças ocorridas interferem no modo de enfretamento e nos papéis assumidos.

A percepção sobre a mudança que os pós-transfundidos começam a vivenciar a partir do processo transfusional traz à tona uma ressignificação da própria vida, influenciada por uma série de incertezas. A relação entre equipe de enfermagem e paciente e seus familiares neste contexto é de inegável importância, pela proximidade e estabelecimento de vínculos de confiança. Os participantes deste estudo mostraram conhecer o processo a que estão sendo submetidos, embora isso não o torne isento de medos. Aponta-se como limitação para este estudo o reduzido número de estudos sobre o tema, constituindo uma lacuna na literatura, além da especificidade da situação vivida pelos participantes (pós-cirúrgicos de cirurgia cardíaca), por si só, já forte em simbolismos. Desta forma, aponta-se para a necessidade de novos estudos, com pacientes de outras especialidades, igualmente dependentes, mesmo que temporariamente, do processo transfusional.

\section{REFERÊNCIAS}

1. Dorneles CC, Bodanese LC, Guaragna JCVC, Macagnan FE, Coelho JC, Borges AP, et al . O impacto da hemotransfusão na morbimortalidade pós-operatória de cirurgias cardíacas. Rev Bras Cir Cardiovasc. 2011;26(2):222-9.

2. Silva KFN, Soares $\mathrm{S}$, Iwamoto $\mathrm{HH}$. A prática transfusional e a formação dos profissionais de saúde. Rev Bras Hematol Hemoter [Internet]. 2009 [acesso em 17 de janeiro de 2013];31(6):421-6. Disponível em: http://www.scielo.br/ pdf/rbhh/v31n6/aop9309.pdf

3. Silva LAA, Somavilla MB. Conhecimentos da equipe de enfermagem sobre terapia transfusional. Cogitare Enferm [Internet]. 2010 [acesso em 17 de janeiro de 2013];15(2):327-33. Disponível em: http://ojs.c3sl.ufpr. br/ojs/index.php/cogitare/article/viewFile/17871/11661

4. Azambuja LEO, Garrafa V. Testemunhas de Jeová ante o uso de hemocomponentes e hemoderivados. AMB Rev Assoc Med Bras. 2010;56(6):705-9.

5. Silva RMG, Kupek E, Peres KG. Prevalência de doação de sangue e fatores associados em Florianópolis, Sul do Brasil: estudo de base populacional. Cad Saúde Pública.
2013;29(10):2008-16.

6. Ministério da Saúde, Secretaria de Atenção à Saúde, Coordenação Geral de Sangue e Hemoderivados. Sangue e hemoderivados: produção hemoterápica [Internet]. Brasília (DF): Ministério da Saúde; 2011 [acesso em 17 de janeiro de 2013]. Disponível em: http://weboffice. macronetwork.com.br/uploads/pro_sangue/arquivos/caderno_informacao_Sangue_e_Hemoderivados_2010.pdf

7. Lefreve F, Lefreve AMC. Discurso do sujeito coletivo: um novo enfoque em pesquisa qualitativa. 2. ed. Caxias do Sul (RS): Educs; 2005.

8. Alfonso-Valdés ME, Bencomo-Hernández AA, Macías-Abraham C, Ballester-Santovenia JM. Desarrollo de la medicina transfusional en el Instituto de Hematología e Inmunología en el período 1996-2010. Rev Cuba Hematol Inmunol Hemoter. 2011;27(1):128-38.

9. Duarte SCM, Stipp MAC, Mesquita MGR, Silva MM. Enfermagem no pós-operatório de cirurgia cardíaca. Esc Anna Nery Rev Enferm. 2012;16(4):657-65.

10. Maldaner CR, Beuter M, Brondani CM, Budó MLD, 
Pauletto MR. Fatores que influenciam a adesão ao tratamento na doença crônica: o doente em terapia hemodialítica. Rev Gaúch Enferm. 2008;29(4):647-53.

11. Andrade ACV, Soratto MT. Educação em saúde para o autocuidado do paciente após cirurgia cardíaca. Saúde Rev [Internet] 2009 [acesso em 17 de janeiro de 2013];11(28/29):37-47. Disponível em: file:///C:/Users/ Cliente/Downloads/47-104-1-PB.pdf

12. Jack $S$, West M, Grocott MP. Perioperative exercise training in elderly subjects. Best Pract Res Clin Anaesthesiol [Internet]. 2011 [cited 2013 January 17];25(3):461-72. Available from: http://www.ncbi.nlm.nih.gov/pubmed/21925410

13. Benetti SRMD, Lenardt MH, Tuoto FS. As transfusões sanguíneas: o sangue e o sistema de conhecimento das pessoas. Cogitare Enferm [Internet]. 2003 [acesso em 17 de janeiro de 2013];8(2):54-60. Disponível em: file:///C:/ Users/Cliente/Downloads/1694-3533-1-PB.pdf

14. Benetti SRD, Lenardt MH. Significado atribuído ao sangue pelos doadores e receptores. Texto \& Contexto Enferm [Internet]. 2006 [acesso em 17 de janeiro de 2013];15(1):43-50. Disponível em: http://www.scielo.br/scielo.php?pid=S01 04-07072006000100005\&script $=$ sci_arttext

15. Pereima RSMR, Reibnitz KS, Martini JG, Nitschke RG. Doação de sangue: solidariedade mecânica versus solidariedade orgânica. Rev Bras Enferm. 2010;63(2):322-7.

16. Novaretti MCZ, Bonifácio SL, Medeiros VR, Ruiz AS, Dorlhiac-Llacer PE, Chamone DAF. Dez anos de experiência em controle de qualidade em imuno-hematologia. Rev Bras Hematol Hemoter [Internet]. 2009 [acesso em 17 de janeiro de 2013];31(3):160-5. Disponível em: http://www.scielo.br/scielo.php?script =sci_arttext\&pid $=$ S1516-84842009000300011

17. Câmara AMCS, Melo VLC, Gomes MGP, Pena BC, Silva AP, Oliveira KM, et al. Percepção do processo saúde-doença: significados e valores da educação em saúde. Rev Bras Educ Méd. 2012;36(Suppl. 1):40-50.

18. Agência Nacional de Vigilância Sanitária (BR). Resolução RDC no 153, de 14 de junho de 2004. Determina o regulamento técnico para os procedimentos hemoterápicos, incluindo a coleta, o processamento, a testagem, o armazenamento, o transporte, o controle de qualidade e o uso humano de sangue, e seus componentes, obtidos do sangue venoso, do cordão umbilical, da placenta e da medula óssea. 2004 [Internet]. Diário Oficial da União 24 Jun 2004 [acesso em 17 de janeiro de 2013]. Disponível em: file:///C:/Users/Cliente/Downloads/arquivo_20110809141139\%20(2).pdf

19. Carrazzone CFV, Brito AM, Gomes YM. Importância da avaliação sorológica pré-transfusional em receptores de sangue. Rev Bras Hematol hemoter [Internet]. 2004 [acesso em 17 de janeiro de 2013];26(2):93-8. Disponível em: http://www.scielo.br/scielo.php?script =sci_arttext\&pid $=$ S1516-84842004000200005

20. Silva Junior JB, Rattner D. Segurança Transfusional: um método de Vigilância Sanitária para avaliação de riscos potenciais em serviços de hemoterapia. Vigilância Sanitária Debate [Internet]. 2014 [acesso em 17 de janeiro de 2013];2(2):43-52. Disponível em: http://www.visaemdebate.incqs.fiocruz.br/index.php/visaemdebate/article/ view/126

21. Ngo LT, Bruhn R, Custer B. Risk perception and its role in attitudes toward blood transfusion: a qualitative systematic review. Transfus Med Rev [Internet]. 2013 [cited 2013 January 17];27(2):119-28. Available from: http://www. ncbi.nlm.nih.gov/pubmed/23499187

22. Agência Nacional de Vigilância Sanitaria (BR). Boletim de Hemovigilância $n^{\circ} 5$ [Internet]. Brasília: Ministério da Saúde; 2012 [acesso em 03 de janeiro de 2013]. Disponível em: http://portal.anvisa.gov.br/wps/wcm/ connect/b38 ebb004dc642d7861dbed6059e5711/ boletim_5_atualizado.pdf?MOD=AJPERES

23. Carvalho RV, Brener S, Ferreira AM, Valle MC, MoraesSouza H. Transfusion practices committee of a public blood bank network in Minas Gerais, Brazil. Rev Bras Hematol Hemoter [Internet]. 2012 [cited 2013 January 17];34(6):416-20. Available from: http://www.ncbi.nlm. nih.gov/pubmed/23323064 